\title{
PERBEDAAN PENURUNAN INDEKS PLAK MENYIKAT GIGI DENGAN TEKNIK BASS DAN ROLL PADA SISWA/I SMP SWASTA GAJAH MADA MEDAN KELAS VII TAHUN 2016
}

\author{
Netty Jojor Aritonang \\ Politeknik Kesehatan Kemenkes Medan Jalan Jamin Ginting KM 13,5
}

\begin{abstract}
Plak gigi merupakan deposit lunak yang melekat erat pada permukaan gigi, terdiri dari mikroorganisme yang berkembang biak dalam suatu matrik interseluler jika seseorang melalaikan kebersihan gigi dan mulutnya. Tujuan dari penelitian ini adalah untuk mengetahui apakah ada perbedaan penurunan indeks plak antara siswa yang menyikat gigi dengan teknik bass dan teknik roll. Jenis penelitian yang digunakan adalah penelitian analitik menggunakan metode eksperimen dengan rancangan Pre-test Dan Post-test Only Group Design tanpa replikasi. Penelitian ini dilakukan pada siswa/i SMP Swasta Gajah Mada Medan Kelas VII Tahun 2016 berjumlah 30 orang dengan pengambilan sampel secara random sampling. Manfaat penelitian ini adalah untuk menambah pengetahuan siswa tentang penurunan indeks plak me nyikat gigi dengan teknik bass dan roll. Hasil yang diperoleh dari penelitian ini menunjukkan bahwa $\mathrm{p}<0,005$ maka hipotesis nol (H0) ditolak, yang berarti terdapat perbedaan sebelum dan sesudah menyikat gigi dengan teknik bass maupun roll terhadap penurunan indeks plak. Sedangkan hasil t-Test independent dengan Equal varians assumed adalah 0,291 dengan probabilitas (Sig) $=0,594$. Melalui uji levene didapatkan nilai p (Sig) 0,305. Berarti varian kedua kelompok adalah sama. Kesimpulan dari penelitian ini adalah pada alpha $5 \%$ tidak ada perbedaan signifikan rata-rata antara menyikat gigi dengan teknik bass dan roll.
\end{abstract}

Kata kunci : Bass, Roll, Indeks Plak

Daftar pustaka : $25(1985$ - 2015)

\section{PENDAHULUAN}

Undang-Undang Kesehatan No. 36 Tahun 2009

Pasal 1 Ayat 1 menyatakan bahwa kesehatan adalah keadaan sehat, baik secara fisik, mental, spiritual, maupun sosial yang memungkinkan setiap orang untuk hidup produktif secara sosial dan ekonomi. Masalah kesehatan gigi di Indonesia masih memerlukan perhatian yang sangat serius karena prevalensi karies dan penyakit periodontal mencapai $80 \%$ dari jumlah penduduk. Upaya untuk mengatasinya sampai saat ini belum menunjukan hasil yang memuaskan. Hal ini dapat dilihat dari indikator kesehatan gigi masyarakat. (Herijulianti, 2001)

Plak gigi merupakan salah satu masalah kesehatan gigi dan mulut yang membentuk suatu biofilm, biasanya kekuningan, yang berkembang secara alami pada gigi. Seperti biofilm, plak gigi terbentuk oleh bakteri kolonial yang berusaha untuk menempel pada permukaan halus dari gigi. Pada awalnya, plak cukup lunak untuk lepas dengan menggunakan kuku jari. Namun, mulai mengeras dalam waktu 48 jam, dan dalam waktu sekitar 10 hari plak menjadi kalkulus (karang gigi) keras dan sulit untuk dihilangkan.

Tidak diragukan lagi bahwa tanpa adanya plak maka tidak akan timbul karies. Namun tidak semua plak menyebabkan karies, hanya plak tertentu yang mengandung koloni mikroba spesifik yang bertanggung jawab terhadap timbulnya karies pada gigi. Akibatnya salah satu cara pencegahan karies adalah dengan mengusahakan agar pembentukan plak pada permukaan gigi dapat dibatasi, yaitu dengan cara menyikat gigi. (Edwina, 1991) Menyikat gigi sangat penting dilakukan dalam mengontrol plak. karena itu semua plak harus dibersihkan. (Tarigan, 2012) salah satu yang mempengaruhi keberhasilan menyikat gigi adalah teknik menyikat gigi. Adapun teknik menyikat gigi adalah cara umum yang dianjurkan untuk membersihkan deposit lunak pada permukaan gigi dan gusi. (Herijulianti, 2012) Teknik bass belakangan ini lebih disukai baik di Inggris maupun di Amerika Serikat, karena teknik bass dinilai cukup efektif dalam membersihkan plak gigi. (Andlaw, 1992) Namun, teknik roll juga merupakan cara yang paling sering dianjurkan karena sederhana tetapi efisien dan dapat digunakan diseluruh bagian mulut. (Herijulianti, 2012) Survey awal yang dilakukan di SMP Swasta Gajah Mada terhadap beberapa siswa ditemukan adanya indeks plak yang tinggi dan belum pernah dilakukan penelitian tentang kesehatan gigi dan mulut di SMP Swasta Gajah Mada Medan Kelas VII.

Berdasarkan latar belakang diatas dan dengan melihat survey awal di SMP Swasta Gajah Mada maka peneliti tertarik untuk mengetahui apakah ada pebedaan penurunan indeks plak antara siswa yang menyikat gigi dengan teknik bass dan teknik roll di SMP Swasta Gajah Mada Medan Kelas VII Tahun 2016. 


\section{Tujuan Penelitian}

Penelitian ini bertujuan untuk mengetahui apakah ada perbedaan penurunan indeks plak antara siswa yang menyikat gigi dengan teknik bass dan teknik roll di SMP Swasta Gajah Mada Tahun 2016.

\section{Manfaat Penelitian}

1. Menambah wawasan siswa/i di SMP Swasta Gajah Mada tentang kesehatan gigi dan mulut khususnya teknik menyikat gigi.

2. Melatih keterampilan siswa/i untuk menyikat gigi dengan teknik yang benar sehingga terhindar dari kerusakan gigi akibat plak.

3. Sebagai bahan masukan bagi peneliti lain untuk melakukan penelitian lebih lanjut.

\section{Kerangka Konsep}

Kerangka konsep penelitian adalah suatu hubungan atau kaitan antara konsep satu terhadap konsep yang lainnya dari masalah yang ingin diteliti. (Notoadmojo, 2005)

\section{Defenisi Operasional}

Untuk mencapai tujuan yang ingin dicapai dalam penelitian ini, penulis menentukan defenisi operasional sebagai berikut :

1. Menyikat gigi dengan teknik bass adalah menyikat gigi dengan teknik dimana sikat gigi diletakkan dengan posisi $45^{\circ}$ menghadap permukaan gigi, digerakkan secara horizontal selama 2 menit.

2. Menyikat gigi dengan teknik roll adalah menyikat gigi dengan sikat gigi digerakkan dengan gerakan berupa lengkunganlengkungan, mulai dari gusi kearah permukaan gigi selama 2 menit.

3. Indeks plak adalah angka yang menunjukkan nilai atau keadaan plak pada permukaan gigi dengan mengukur setiap gigi indeks dengan empat permukaan.

\section{Hipotesis}

Hipotesis adalah jawaban sementara terhadap rumusan penelitian.

Ho : tidak ada perbedaan penurunan indeks plak antara siswa yang menyikat gigi dengan teknik bass dan teknik roll.

$\mathrm{Ha}$ : ada perbedaan penurunan indeks plak antara siswa yang menyikat gigi dengan teknik bass dan teknik roll

\section{Jenis dan Desain Penelitian}

Jenis penelitian yang dipakai pada penelitian ini adalah eksperimen pre and post only group desain yaitu perbandingan indeks plak sebelum dan sesudah menyikat gigi dengan teknik bass dan teknik roll pada siswa/i SMP Swasta Gajah Mada Medan Kelas VII Tahun 2016.

$\begin{array}{lll}\mathrm{O} 1 & (\mathrm{X} 1) & \mathrm{O} 2 \\ \mathrm{O} 3 & (\mathrm{X} 2) & \mathrm{O} 4\end{array}$

Keterangan Gambar :

O1 : Mengukur indeks plak sebelum menyikat gigi dengan teknik bass.

$\mathrm{X} 1$ : Perlakuan berupa kegiatan menyikat gigi dengan teknik bass.

O2 : Mengukur indeks plak sesudah menyikat gigi dengan teknik bass.

O3 : Mengukur indeks plak sebelum menyikat gigi dengan teknik roll.

X2 : Perlakuan berupa kegiatan menyikat gigi dengan teknik roll.

O4 : Mengukur indeks plak sesudah menyikat gigi dengan teknik roll.

\section{Hasil Penelitian}

Analisa Univariat

Data yang dikumpulkan adalah hasil penelitian yang dilakukan terhadap siswa/i SMP Swasta Gajah Mada Medan Kelas VII. Pengumpulan data dilakukan dengan pemeriksaan langsung kerongga mulut siswa/i yang menjadi sampel. Dari penelitian yang dilakukan, maka diperoleh data siswa, skor indeks plak sebelum dan sesudah menyikat gigi dengan teknik bass dan teknik roll. Setelah seluruh data terkumpul, maka dibuat analisa data dengan cara membuat tabel distribusi frekuensi untuk masing-masing kelompok sampel. Kemudian dilakukan pengolahan data secara statistik dengan menggunakan uji tTest.

\section{Analisa Bivariat \\ Dependent t-Test}

Untuk menguji dua sampel yang berpasangan maka digunakan paired sample t-Test. Uji t-Test dependent berpasangan ini dapat mengetahui apakah ada perbedaan menyikat gigi dengan teknik bass dan teknik roll terhadap penurunan indeks plak. Adapun hasil dari t-Test dependent yang dilakukan dengan program computer.

Paired Sample Statistik Untuk kelompok Menyikat Gigi dengan Teknik Bass

\begin{tabular}{llllllllll}
\hline Teknik & Rata-Rata & & & & & & \multicolumn{2}{c}{ CI 95\% } \\
Menyikat & $\mathrm{IP}$ & $\mathrm{N}$ & $\mathrm{T}$ & $\mathrm{Std}$ & $P$ & $\mathrm{df}$ & & \\
\cline { 5 - 9 } Gigi & & & & & & & & Bawah & Atas \\
\hline Bass & 1,959 & 15 & 52,68 & 0,144 & 0,000 & 14 & 1,88 & 2,04 \\
\hline
\end{tabular}


Dari tabel diatas dapat diketahui bahwa probabilitas adalah 0,000. Oleh karena probabilitas $\mathrm{p}<0,005$ maka H0 ditolak, yang artinya terdapat perbedaan sebelum dan sesudah menyikat gigi dengan teknik bass terhadap penurunan indeks plak.

Paired Sample Statistik Untuk kelompok Menyikat Gigi dengan Teknik Roll

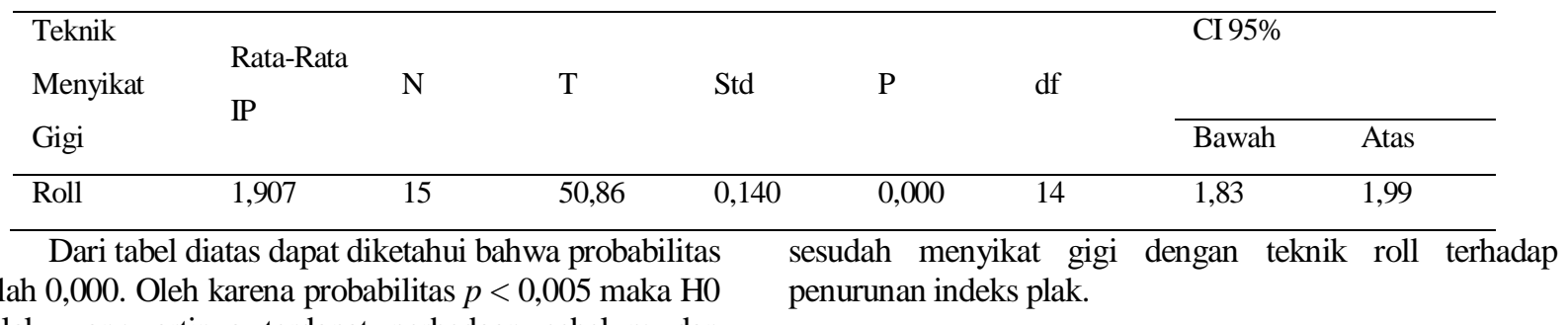

adalah 0,000 . Oleh karena probabilitas $p<0,005$ maka HO

ditolak, yang artinya terdapat perbedaan sebelum dan

Perbedaan antara menyikat gigi dengan teknik bass dan roll terhadap
penurunan indeks plak pada siswa/i SMP Swasta Gajah Mada Kelas VII

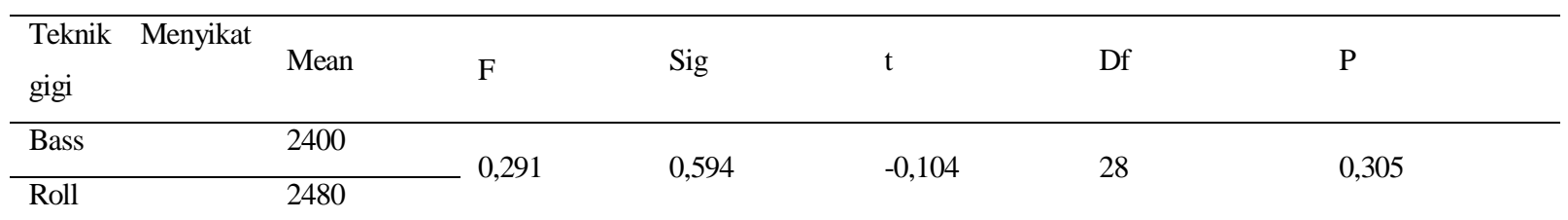

Dari hasil pemeriksaan diketahui bahwa $\mathrm{f}_{\text {hitung }}$ untuk uji sampel t-Test independent dengan Equal varians assumed adalah 0,291 dengan probabilitas (Sig) $=0,594$. Melalui uji levene didapatkan nilai $p$ (Sig) 0,305 . Berarti varian kedua kelompok adalah sama. Dari hasil diatas didapat nilai $p(\mathrm{Sig})=0,305$ sehingga dapat disimpulkan bahwa pada alpha 5\% tidak ada perbedaan signifikan rata-rata antara menyikat gigi dengan teknik bass dan roll.

\section{Pembahasan}

Penelitian ini mengambil sampel sebanyak 30 siswa/i SMP Swasta Gajah Mada Medan Kelas VII yang dipilih secara acak dan dibagi menjadi dua kelompok. Kelompok pertama menyikat gigi dengan teknik bass dan kelompok kedua menyikat gigi dengan teknik roll. Dalam penelitian ini tidak dilakukan replica. Plak adalah lapisan tipis mikroorganisme, sisa makanan dan bahan organik yang terbentuk di gigi, kadang-kadang juga ditemukan pada gusi dan lidah. Plak merupakan penyebab lokal dan utama yang terbentuknya penyakit gigi dan mulut yang lain seperti karies, kalkulus, gingivitis, periodontitis dan lain sebagainya. Oleh karena plak tidak dapat dihindari pembentukannya, maka mengurangi akumulasi plak adalah hal yang sangat penting untuk mencegah terbentuknya penyakit gigi dan mulut. Pengendalian plak bisa dilakukan secara mekanis dan kimiawi. (Anggreini, 2007)

Berdasarkan hasil pemeriksaan awal yang telah dilakukan terhadap seluruh sampel teradapat 4 pemeriksaan dengan kriteria sedang dan 11 pemeriksaan dengan kriteria buruk sebelum menyikat gigi dengan teknik bass. Setelah menyikat gigi dengan teknik bass indeks plak menurun yaitu seluruh responden mendapat kriteria baik. Sedangkan pada pemeriksaan awal sebelum menyikat gigi dengan teknik roll terdapat 6 pemeriksaan dengan kriteria sedang dan 9 pemeriksaan dengan kriteria buruk. Setelah menyikat gigi dengan teknik roll indeks plak menurun yaitu seluruh responden mendapat kriteria baik. Dari hasil uji t-Test dependent kedua variabel tersebut didapat hasil bahwa $\mathrm{p}<0,05$ atau 0,000 $<0,05$ sehingga hipotesis nol (H0) ditolak yang berarti bahwa kedua teknik menyikat gigi ini sama-sama berpengaruh terhadap penurunan indeks plak. Untuk mengetahui apakah ada perbedaan selisih indeks plak rata-rata antara menyikat gigi dengan teknik bass dan roll terhadap penurunan indeks plak dilakukan uji t-Test independent. Melalui hasil perhitungan uji t-Test independent yang telah dilakukan dengan program komputer, melihat dari nilai equal varians assumed diperoleh $t_{\text {hitung }}$ (diasumsikan kedua varians sama atau tidak berbeda) adalah 0,291 dengan probabilitas 0,594. Dari hasil diatas dapat didapat nilai $\mathrm{p}=0,305$ sehingga dapat disimpulkan bahwa pada alpha 5\%, tidak ada perbedaan signifikan rata-rata antara menyikat gigi dengan teknik bass dan roll. penelitian ini telah mengendalikan variabel pengganggu dengan menyamakan jenis sikat dan pasta gigi yang digunakan serta waktu menyikat gigi untuk semua responden.

Hal ini sesuai dengan teori yang menyatakan bahwa teknik apapun yang digunakan, tujuan utama menyikat gigi adalah menyingkirkan plak dari permukaan gigi dan sulkus gingiva, dengan kerusakan jaringan pendukung seminimal mungkin. (Pintauli,2008)

\section{Simpulan}

Dari hasil penelitian yang telah dilakukan oleh peneliti terhadap siswa/i SMP Swasta Gajah Mada Medan Kelas VII maka didapat kesimpulan bahwa :

1. Indeks plak sebelum menyikat gigi dengan teknik bass yaitu antara 1,87-2,45 dimana terdapat 4 pemeriksaan dengan kriteria sedang dan 11 pemeriksaan dengan kriteria buruk.

2. Indeks plak setelah menyikat gigi dengan teknik bass yaitu antara 160,37 termasuk dalam kriteria baik. 
3. Indeks plak sebelum menyikat gigi dengan teknik roll yaitu antara 1,91 - 2,6 yaitu 6 pemeriksaan dengan kriteria sedang dan 9 pemeriksaan dengan kriteria buruk.

4. Indeks plak setelah menyikat gigi dengan teknik roll yaitu antara 0,16 - 0,5 yaitu seluruh responden mendapat kriteria baik.

5. Hasil perhitungan dari uji t-Test dependent bahwa kedua teknik menyikat gigi ini sama-sama berpengaruh terhadap penurunan indeks plak. Dari hasil pemeriksaan uji t-Test independent dengan nilai equal varians assumed diperoleh $t$ hitung (diasumsikan kedua varians sama atau tidak berbeda) adalah 0,291 dengan probabilitas 0,594. Dari hasil diatas dapat didapat nilai $\mathrm{p}=0,305$ sehingga dapat disimpulkan bahwa pada alpha 5\%, tidak ada perbedaan signifikan rata-rata antara menyikat gigi dengan teknik bass dan roll.

\section{Saran}

Dengan selesainya penelitian ini, diharapkan :

1. kepada siswa/i SMP Swasta Gajah Mada Medan untuk menggunakan teknik menyikat gigi seperti teknik bass dan roll dalam menjaga kesehatan gigi dan mulut .

2. Kepada pihak sekolah SMP Swasta Gajah Mada Medan untuk bekerja sama dengan puskesmas setempat dalam meningkatkan derajat kesehatan gigi dan mulut.

3. Kepada mahasiswa agar hasil penelitian ini dapat berguna sebagai bahan masukan bagi peneliti lain untuk melakukan penelitian lebih lanjut.

\section{DAFTAR PUSTAKA}

Alburger, S, 2011. The Rolling Method of Brushing Teeth, http://www.ehow.com/info_8583760_rollingmethod-brushing-teeth.html diakses pada tanggal 12 maret 2015

Andlaw, R.J. 1992. Perawatan Gigi Anak. Widya Medika. Jakarta

Arikunto, 2008. Prosedur Penelitian Suatu Pendekatan Praktik, PT RINEKA CIPTA, Jakarta

Besford, J, 1996. Mengenal Gigi Anda Petunjuk Bagi Orang Tua.Ed.2. Arcan. Jakarta

Bhawani, C, 2010, Bass Tooth Brushing Technique For Gingiva and Subgingiva Cleaning. http://dentistryforstudents.com/bass-toothbrushingtechnique diakses pada tanggal 10 maret 2015

Boedihardjo, 1985. Pemeliharaan Kesehatan Gigi Keluarga. Airlangga University Press. Surabaya

Daliemunthe, S.H. 2008. Perbandingan Penurunan Skor Plak. USU Press. Medan

Depkes RI, 2010. Tujuan Pembangunan Kesehatan, Jakarta

Edwina, A.M, 1991. Dasar-Dasar Karies Gigi. EGC. Jakarta
Forrest, J.O, 1995. Pencegahan Penyakit Mulut, Jakarta

Hastono, P.S. 2001, Modul Analisa Data. Fakultas Kesehatan Masyarakat UI, 2001

Herijulianti, E, dkk, 2012. Ilmu Penyakit Jaringan Keras dan Jaringan Pendukung Gigi. EGC. Jakarta

Hongini, S, 2012. Kesehatan Gigi dan Mulut. Reka Cipta. Bandung

Machfoedz, I, 2005. Menjaga Kebersihan Gigi dan Mulut. EGC. Jakarta

Notoadmodjo, S, 2010. Metodologi Penelitian Kesehatan. PT Rineka Cipta. Jakarta

Pintauli, S, 2010. Menuju Gigi \& Mulut Sehat. USU Press. Medan

Pratiwi, D, 2007. Gigi Sehat dan Cantik. EGC. Jakarta

Putri,2010.Plakhttp://www.nadiatiaraputri.co.cc// 2010/12/07 diakses pada tanggal 30 juni 2015

Ramadhan, Ardyan. G, 2010. Serba-Serbi Kesehatan Gigi \& Mulut. Bukune, Jakarta

Tarigan, S, 2012. Karies Gigi. Ed.2. EGC. Jakarta

Warsidi, E, 2010. Menjaga Kebersihan Gigi dan Mulut. Quadra. Jakarta

Yulisa, D, 2012. Apa itu plak gigi http://dianyulisady.wordpress.com/2012/03/26/apaitu-plak-gigi/diakses pada 2 juli 2015

Yundali, S, 2012. Karies Gigi, PT RINEKA CIPTA, Jakarta 